\title{
Spontaneous intracerebral hemorrhage and the challenge of surgical decision making: a review
}

\author{
Michael L. Kelly, M.D., ${ }^{1}$ Daniel P. Sulmasy, M.D., Ph.D., ${ }^{2}$ and Robert J. Weil, M.D. ${ }^{1,3}$ \\ ${ }^{1}$ Department of Neurosurgery, Neurological Institute, Cleveland Clinic Foundation, Cleveland, Ohio; \\ ${ }^{2}$ MacLean Center for Clinical Medical Ethics, Department of Medicine, The University of Chicago, Illinois; \\ and ${ }^{3}$ Rose Ella Burkhardt Brain Tumor and Neuro-Oncology Center, Cleveland Clinic Foundation, \\ Cleveland, Ohio
}

\begin{abstract}
Decision making for patients with spontaneous intracerebral hemorrhage (ICH) poses several challenges. Outcomes in this patient population are generally poor, prognostication is often uncertain, and treatment strategies offer limited benefits. Studies demonstrate variability in the type and intensity of treatment offered, which is attributed to clinical uncertainty and habits of training. Research has focused on new techniques and more stringent evidencebased selection criteria to improve outcomes and produce consensus around treatment strategies for patients with ICH. Such focus, however, offers little description of how ICH treatment decisions are made and how such decisions reflect patient preferences regarding medical care. A growing body of literature suggests that the process of decision making in ICH is laden with bias, value assumptions, and subjective impressions. Factors such as geography, cognitive biases, patient perceptions, and physician characteristics can all shape decision making and the selection of treatment. Such factors often serve as a barrier to providing patient-centered medical care. In this article, the authors review how surgical decision making for patients with $\mathrm{ICH}$ is shaped by these decisional factors and suggest future research pathways to study decision making in ICH. Such research efforts are important for establishing quality guidelines and pay-for-performance measures that reflect the preferences of individual patients and the contextual nature of medical decision making.

(http://thejns.org/doi/abs/10.3171/2013.2.FOCUS1319)
\end{abstract}

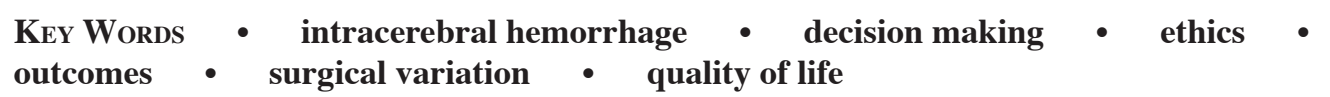

Disease generally begins that equality which death completes...where all human glory is obliterated, the wit is clouded, the reasoner perplexed, and the hero subdued...

Samuel Johnson, The Rambler, No. 48 (1750)

Surgical decision making for patients with spontaneous ICH remains problematic. The benefits of intervention are unclear and intervention frequency and distribution are highly variable among countries, institutions, and individual physicians. Much of the clinical research targeting treatment for ICH presumes that improved techniques or better evidence-based selection criteria will build consensus around treatment decisions and reduce decisional uncertainty. These efforts, however, address only part of the problem.

A growing body of literature suggests that the process of clinical decision making has a profound impact on treatment decisions and patient outcomes. ${ }^{89}$ Factors affecting the decision-making process are multiple and

\footnotetext{
Abbreviations used in this paper: $\mathrm{ICH}=$ intracerebral hemorrhage; $\mathrm{mRS}=$ modified Rankin Scale; $\mathrm{QOL}=$ quality of life; $\mathrm{STICH}$ $=$ Surgical Trial in Intracerebral Haemorrhage.
}

include physician heuristics and biases, institutional practices, interpretation of disparate and sometimes conflicting medical evidence, and implementation of patient preferences ${ }^{40,80}$ Improving care for patients with ICH requires an investigation of how neurosurgeons make treatment decisions, what biases and heuristics influence this process, and how this process relates to a patient's known wishes or anticipated desires concerning treatment. In this article, we explore the decisional factors related to management of patients with ICH and suggest future research pathways that may improve our understanding of how these factors influence treatment decisions and patient care.

\section{Intracerebral Hemorrhage, Evidence, and Uncertainty}

Reciting the dismal morbidity and mortality statistics for patients with ICH has become an unfortunate ritual in the ICH literature these days. Despite great effort, ICH comprises approximately $10 \%-15 \%$ of all stroke types and carries an estimated 30-day mortality rate of 31\%$59 \% .{ }^{25,66}$ Functional outcomes are equally disappointing, in which only $20 \%$ of patients become functionally inde- 
pendent at 3 months. ${ }^{52,68}$ Treatment, whether nonsurgical or surgical, has limited benefit in many cases but has economic and functional costs for the patient and society. ${ }^{70,71}$

Considerable effort has been devoted to identifying outcome predictors in patients with ICH. These models have included factors such as the Glasgow Coma Scale, ICH volume and location, age, presence of hydrocephalus, and intraventricular hemorrhage. ${ }^{32}$ Prognostication in ICH remains problematic despite these well-established risk factors and a multitude of predictive models..$^{14,34}$ The predictive value of such models has been hampered by variability in outcomes measured, poor prognostic accuracy, and limited practical application and external validity. ${ }^{36}$

Moreover, individual clinical prognostication fares little better among critically ill neurological patients. Becker et al. ${ }^{7}$ showed prognostic heterogeneity among neurologists and neurosurgeons in hypothetical ICH case scenarios. Finley Caulfield et al. ${ }^{24}$ reported more than $90 \%$ accuracy among neurointensivists in predicting poor prognosis among mechanically ventilated neurological patients compared with actual outcome, but these clinicians achieved only $63 \%$ accuracy in predicting good functional outcome and were even less accurate in predicting QOL among survivors.

Compounding prognostic uncertainty are studies that document poor outcomes and inconclusive results from surgical therapy for ICH. Historically, randomized trials have been few in number with small sample sizes and conflicting results. ${ }^{5,39,49}$ Subsequent meta-analyses have failed to show much benefit for surgery. ${ }^{22,28}$

The STICH trial suggested a nonsignificant trend toward more favorable outcomes with surgery for superficial lobar hemorrhages, but this trial suffered from preselection of operative candidates and crossover of approximately one-fourth of the patients into the surgical arm. ${ }^{50,54} \mathrm{~A}$ more recent retrospective review of national trends in the US by Patil et al. ${ }^{58}$ confirmed high morbidity and mortality rates after operative management of ICH despite advances in technique and more selective operative criteria. These results have led many to advocate a highly conservative stance toward surgery for patients with ICH with more rigid selection criteria for treatment. ${ }^{48,55}$

Given the inaccuracies of prognostication and the uncertainty of treatment effect, it is perhaps not surprising that studies report highly variable treatment patterns for patients with ICH. The STICH investigators found significant variations in operative rates for ICH among participating countries. ${ }^{29}$ This variation could not be explained by population differences and was believed to be secondary to institutional culture or habits of physician training. ${ }^{29,35}$

In the US, Andaluz and Zuccarello ${ }^{3}$ reported limited geographic variability in the treatment of ICH using the nationwide inpatient data sample. However, Patil et al. ${ }^{58}$ reported significant operative rate variability among institutions using the same data set. The effect of recent trials on operative rates has been mixed, with some institutions reporting a decline in rates of surgery for $\mathrm{ICH}$ while others report these rates to be stable.,44

Survey data suggests individual clinician variability in surgical decision making for patients with ICH. Fer- nandes and Mendelow ${ }^{23}$ reported decisional uncertainty among $81 \%$ of surveyed neurosurgeons. The authors also noted variation in neurosurgeons' attitudes toward surgery when considering hemorrhage location, size, poor clinical condition, and timing of surgery. More recent survey data suggest stability in these attitudes despite recent trial results and confirm the heterogeneity of treatment decisions for ICH patients in poor clinical condition. ${ }^{69}$

It is important to note here that variability in the treatment of patients with $\mathrm{ICH}$ is often explained by or dismissed on the basis of poor clinical evidence and the need for better data. The assumption is that better evidence and more outcomes data will bolster a treatment consensus, reduce variability, and improve patient outcomes. Such reasoning is evident in the published STICH II trial protocol. ${ }^{51}$

While narrowing selection criteria might prove helpful to establish a clear, evidence-based indication for surgery, it does little to acknowledge patient wishes concerning such an intervention and how such wishes might be identified. Patients with an ICH, and/or their surrogate decision makers, face a myriad of treatment and/or palliative decisions not addressed by most study data. These decisions are based on patient preferences in addition to objective efficacy- or outcome-based criteria. These decisions are constrained not only by lacunes (gaps) in data or predictive outcomes, but also by time. This disjunction between medical evidence and patient wishes creates a tension in the ICH decision-making process. Quill and others have termed this divide the "preference-practice gap." 65

\section{Decision Making in ICH}

The recent literature on $\mathrm{ICH}$ treatment and outcomes reflects this tension between evidence and preferencedirected medical care. Many clinicians assume that simply establishing clear treatment guidelines will, by itself, reduce treatment variability and improve outcomes. Such thinking, however, disregards the preference-sensitive nature of medical decision making and previously recognized sources of surgical practice variation. ${ }^{89}$

Decision making for a patient with ICH involves assessing tradeoffs among operative and nonoperative, or active and passive, treatment options. In deciding for or against surgery, for example, patients or their surrogate decision makers must weigh the benefit of improved survival with the risk of often severe functional disability. This decision is often only the first of many such decisions, which might include mechanical ventilation, CSF diversion, and supplemental nutrition and hydration. Such decisions are inescapably individualized and value based. ${ }^{42}$ Some patients might choose maximal intervention while others might opt for more conservative measures. Few studies describe how such decisions are made and how the quality of such decisions might be assessed. ${ }^{74}$

\section{Autonomy and the Patient With ICH}

Medical ethics classically teaches that such treatment decisions should respect patient autonomy. ${ }^{6}$ The assumption is that patients have the right to assess risks 
and benefits for themselves and make their own treatment decisions. In most patients with $\mathrm{ICH}$, autonomous decision making is not possible and so a surrogate decision maker is asked to make a "substituted judgment" on the patient's behalf.

Substituted judgment is believed to extend patient autonomy when the patient is incapacitated. Typically, a family member attempts to recall what the patient would have wanted if he/she could make the decision and uses this recollection as a basis for the treatment decision. For patients whose wishes are not known and for whom no surrogate decision maker is available, a "best interest" standard is then applied.9,59

Recently, the utility of this standard decision-making model has been questioned and much of the concern relates to the accuracy of the substituted judgment standard. Critics argue that proxies perform no better than chance in predicting a patient's wishes in hypothetical scenarios. ${ }^{62}$ Studies have also found that treatment wishes often resemble the surrogate's own wishes ${ }^{21}$ and that physicians fare worse than any other proxy subgroup in determining patients' wishes regarding health care..$^{57}$

A recent meta-analysis found equally poor surrogate accuracy when considering health states such as stroke and intervention types such as surgery. ${ }^{75}$ Moreover, families and surrogates report poor communication about preferences for life-sustaining care during prolonged stays in the intensive care unit. ${ }^{79}$ Surrogates charged with making medical decisions with little physician support have reported greater dissatisfaction with medical care overall. ${ }^{30,84}$

Surrogate inaccuracy is considered to be a product of two types of error known as the "disability paradox" and the "focusing illusion."16,72,78 A study of patients with spinal cord injury in the 1970s showed that self-reported QOL among these patients was not substantially different from recent lottery winners. ${ }^{8}$ Since that time, studies have shown that individuals with severe disabilities report greater QOL than those reported by healthy subjects in hypothetical scenarios. ${ }^{81}$ These patients adjust to changes in life circumstances over time by altering and recalibrating their standards, values, and emotional responses toward disability and health, a process known as "response shift."'10

The failure of surrogates to account for the disability paradox is due to a "focusing illusion" or the tendency of decision makers to focus on changes in a health state rather than features in a health state that remain constant. ${ }^{81}$ Such a focus tends to emphasize disability such as hemiplegia or aphasia rather than benefits such as survival and limited social interaction. In the stroke literature, studies have shown that healthy individuals decline life-saving interventions in hypothetical situations out of concern for disability. ${ }^{45}$ However, patients who have undergone decompressive hemicraniectomy for malignant middle cerebral artery stroke report a willingness to undergo the procedure again under similar circumstances. ${ }^{83}$

Moreover, recent data suggest that the idea of autonomous decision making based solely on personal preferences might not be something patients desire. In a study by Sulmasy et al., ${ }^{76}$ a majority of terminally ill patients preferred a model of shared decision making rather than pure substituted judgments. Sulmasy and Snyder ${ }^{77}$ argue that a hierarchical model of decision-making standards does not reflect clinical reality or the preferences of patients and their families. Physicians and families should focus decisions on a patient's underlying values rather than imperfectly knowable preferences regarding unforeseeable circumstances. Such a process acknowledges the limitations of surrogate decision making in complex clinical situations. Again, the heuristics and biases that influence and obscure judgments under uncertainty-especially in a time-constrained, emotionally charged environment-are extremely important. ${ }^{47}$ This vital and broad topic is beyond the scope of this review, but has been amply covered by Kahneman in his recent book..$^{40}$

\section{Regional Bias}

The limitations of preference-based decision making do not by themselves account for all of the problems encountered in the ICH decision-making process. A growing body of literature suggests that simply eliciting patient preferences in a clinical encounter does little to explain observed variations in surgical treatment patterns. ${ }^{89} \mathrm{~A}$ large number of studies have shown that procedural rates for hip and knee replacements, tonsillectomy, prostatectomy, back surgery, and cardiac catheterization all show wide geographic variability. ${ }^{87,88,90,91}$

Such variation is unexplained by recorded patient preferences for surgery or the prevalence of disease in the population..$^{38}$ Much of the work of the Dartmouth Atlas ${ }^{61}$ has demonstrated how these patterns relate to local physician supply, institutional infrastructure, alternative treatment options, and regional professional opinion. Collectively, these data suggest that institutional factors and regional practice culture play a dramatic role in how physicians manage patients and make treatment decisions.

A similar picture appears to be emerging in the treatment of stroke and ICH. Hemphill et al. ${ }^{31,33}$ have demonstrated an association between ICH mortality rates and hospital do-not-resucitate order utilization patterns. Operative rates for $\mathrm{ICH}$ also vary between institutions..$^{58}$ The multinational STICH data confirms variability on an international scale. ${ }^{29}$ Survey data also confirms the likelihood of individual variability among clinicians caring for patients with $\mathrm{ICH} .^{22}$

\section{Information Bias}

Part of treatment variability in ICH can also be attributed to the way in which information is communicated in the acute care setting. This process suffers from multiple sources of error. Basic survival estimates in ICH are limited due to high rates of withdrawal of care, which masks the natural history of survival in this population. Recent estimates attribute $40 \%$ of the observed mortality in ICH to withdrawal of care practices. ${ }^{43}$ These estimates are believed to have produced a general sense of futility among many clinicians when treating patients with $\mathrm{ICH} .{ }^{7,34}$ The effects of framing bias have also been described. ${ }^{67} \mathrm{Re}-$ porting mostly negative outcomes, emphasizing the impact of disabilities, and providing few or selective details on treatment options have been shown to influence patient and/or surrogate treatment decisions. ${ }^{2}$ 
Studies have also shown that presentation style and patient perception of prognostic information influence treatment decisions. ${ }^{85}$ Several factors have been associated with how patients perceive their prognosis, including: the order in which information is presented, the selection of time frame for outcomes, the use of relative risk rather than absolute risk reduction, the use of proportions versus probabilities, and the use of graphic representations of outcomes. ${ }^{19}$ Physician statistical literacy has proven an additional barrier to effective patient communication and decision making as well. ${ }^{86}$

\section{Personal Bias}

The notion that clinicians influence decision making or carry personal bias regarding treatment options may not appear surprising at first glance. Studies on physicians' influence in medical decision making, however, demonstrate clear associations with practice patterns, some related to life-and-death decisions. One recent study showed a 15fold range in withdrawal of care rates among intensivists working in the same intensive care unit. The decision to withdraw support was more strongly associated with the individual clinician than with patient comorbid conditions, diagnostic category, and source of intensive care unit admission. ${ }^{27}$

Studies have shown that physician personal characteristics such as years in practice, attitudes toward medical care, and religious beliefs are associated with decisions to withdraw life support. ${ }^{11,12,73}$ Physician behaviors have also been associated with financial incentives. ${ }^{18}$ Clinicians are known to be overly optimistic with regard to cancer prognosis and overly pessimistic after severe stroke, especially after an ICH. ${ }^{13,15-17,24}$ Sources of error that cloud surrogate decision making such as the focusing illusion appear to also hold true for clinicians when making decisions for, and with, patients. ${ }^{16,41,47,78}$ Despite these data, the influence of physicians on medical decision making often goes unacknowledged in the medical literature and, to an even greater degree, in the surgical literature.

\section{Quality of Life}

Quality of life is a major conceptual issue that underlies much of the debate over bias, variation, and decisionmaking patterns. ${ }^{82}$ Stroke patients who have undergone craniectomy are known to have significantly worse QOL scores, which worsen with increasing age, the presence of 1 or more neurological deficits, and prolonged duration of mechanical ventilation. ${ }^{26}$ However, patients with severe disease or disability do not necessarily report poor QOL in all cases. ${ }^{20}$ Attempts to understand determinants of QOL in neurosurgical patients have proven somewhat problematic. For example, predictive factors for poor QOL have shown high variance and mental QOL measures have proven inaccurate in the well-studied subarachnoid hemorrhage population. ${ }^{56}$

Quality of life is also implicit in commonly used disability outcome scales such as the Barthel Index and the mRS. Studies often establish cutoff points for favorable or unfavorable outcomes based on arbitrary distinctions made between an mRS score of 4 (requiring assistance with basic needs and walking) and an mRS score of 3 (able to walk unassisted). Such distinctions do not necessarily reflect the outcome that an individual values. ${ }^{63}$

Using such metrics to make surgical decisions thereby suffers from the same inaccuracies attributed to surrogate decision making under a substituted judgment standard. Unacknowledged value judgments regarding ambulation, self-care, and verbal communication, to name a few, often drive physician perception of outcome, a perception that may or may not be shared by patients.

\section{Future Directions}

Given the present state of understandable pessimism regarding the treatment and management of patients with ICH, calling attention to biases and inaccuracies in the decision-making process might appear counterproductive. Studying the vagaries and variations of clinical decision making and practice patterns in such a poor climate might risk making matters worse. Several of these problems, however, are likely responsible for the frustration experienced by clinicians, patients, and families in many instances.

Fundamentally, decision making in ICH is challenging because of the nature of the disease and the limited treatment options. Efforts to improve prevention, prognostication, medical therapy, surgical technique, and treatment selection criteria constitute the most powerful ways to improve decision making in this population. However, such improvements are likely to help only some patients with ICH, likely those who are younger, healthier, and treated earlier. For the rest of the population who fall into prognostically "unfavorable" categories, decision making will remain difficult. Such decisions fall under what Tversky and Kahneman ${ }^{80}$ recognized as judgments under uncertainty, decisions influenced by heuristics and biases, which need to be carefully evaluated and considered when making an authoritative action, especially when time constrained.

In summary, few studies have described how clinical decisions are made for patients with ICH. Patient wishes concerning treatment options in ICH are largely unknown, particularly in actual clinical situations. As such, outcome scales and population-based QOL measures carry limited value when assessing a particular patient's preferences concerning treatment. How do we know which patients find an mRS score of 4 acceptable and which do not? Justifying treatment decisions based on categorical distinctions in scale scores made by investigators rather than based on individual patient preferences might not adequately serve either patients' interests or clinicians' understanding of their patients.

Given the paucity of good choices, however, the ethical principle of autonomy may not be as salient in decision making for patients with ICH as it is in other contexts. An emphasis on patient autonomy and treatment preferences may have obscured our understanding of the decision-making process. ${ }^{4}$ Approximately $25 \%$ of US patients have completed an advance directive, ${ }^{46}$ and of that number very few are likely to have stated their $\mathrm{ICH}$ treatment preferences in great detail. Furthermore, 
medical decision making is a two-sided process involving clinician and patient. Few studies have examined this dynamic process among patients with ICH. To our knowledge, no studies have examined this process with regard to surgical decision making in patients with an ICH.

The task, then, is to study the decision-making process directly in patients with ICH. This task includes investigating how patients or their surrogates make decisions concerning treatment in actual clinical situations or, at the very least, in hypothetical scenarios. More data are needed to describe patient-reported outcomes after interventions such as craniotomy for ICH to assess the effect of surgery on patient-based QOL measures. Such work should also assess how self-reported QOL might evolve temporally after ICH and which factors influence these developments. Research should also focus on how surgeons shape the ICH decision-making process and how patterns of decision making might relate to patient characteristics, a project that is currently being undertaken by the authors. Such data would benefit not only practicing neurosurgeons, but also trainees as they learn to navigate ICH management decisions.

These efforts should be designed to improve what some authors have termed "preference-based medicine" in neurosurgery as opposed to purely evidence-based medicine standards. ${ }^{16}$ Evidence-based medicine does little to guide decision making for particular patients, especially when such standards are independent of patient values and subject to clinician bias and misinterpretation..$^{53}$ The recent Institute of Medicine report Crossing the Quality Chasm $^{37}$ addressed some of these concerns and made patient-centered care 1 of 6 goals for quality improvement.

Developing a preference-based medicine standard will improve our understanding of patient attitudes toward ICH treatment options. It will also serve to guide the selection of appropriate therapies based on a patient's values concerning health care. ${ }^{64}$ Such a focus is important for establishing quality guidelines and pay-for-performance measures that reflect the needs of a particular patient and the contextual nature of medical decision making, rather than measures divorced from such realities. $^{74}$ The ultimate goal is to enhance neurosurgical clinical judgment, which should be directed toward achieving the good of a particular patient at a certain point in time. As Pellegrino and Thomasma write, "Much of the cost of medical care and even its outcome and satisfaction for the patient, can turn on how the clinician plays the 'game' of clinical judgment." ${ }^{60}$ While a matter as significant as $\mathrm{ICH}$ is not a game, much does ride on how judgments are made under conditions of profound uncertainty by those who care for such patients. If the quality of these judgments is to be improved, it might be wise to start by sharpening our understanding of how decision making for ICH patients currently takes place.

\section{Disclosure}

The authors report no conflict of interest concerning the materials or methods used in this study or the findings specified in this paper.

Author contributions to the study and manuscript prepara- tion include the following. Conception and design: all authors. Acquisition of data: Kelly. Analysis and interpretation of data: all authors. Drafting the article: Kelly. Critically revising the article: all authors. Reviewed submitted version of manuscript: all authors. Approved the final version of the manuscript on behalf of all authors: Kelly. Administrative/technical/material support: all authors. Study supervision: Sulmasy, Weil.

\section{Acknowledgments}

The authors wish to thank the Melvin Burkhardt Chair in Neurosurgical Oncology and the Karen Colina Wilson research endowment within the Brain Tumor and Neuro-Oncology Center at the Cleveland Clinic Foundation (R.J.W.).

\section{References}

1. Adeoye O, Ringer A, Hornung R, Khatri P, Zuccarello M, Kleindorfer D: Trends in surgical management and mortality of intracerebral hemorrhage in the United States before and after the STICH trial. Neurocrit Care 13:82-86, 2010

2. Ainslie N, Beisecker AE: Changes in decisions by elderly persons based on treatment description. Arch Intern Med 154: 2225-2233, 1994

3. Andaluz N, Zuccarello M: Recent trends in the treatment of spontaneous intracerebral hemorrhage: analysis of a nationwide inpatient database. Clinical article. J Neurosurg 110: 403-410, 2009

4. Baron J: A decision analysis of consent. Am J Bioeth 6:4652, 2006

5. Batjer HH, Reisch JS, Allen BC, Plaizier LJ, Su CJ: Failure of surgery to improve outcome in hypertensive putaminal hemorrhage. A prospective randomized trial. Arch Neurol 47: 1103-1106, 1990

6. Beauchamp TL, Childress JF: Principles of Biomedical Ethics, ed 5. New York: Oxford University Press, 2001

7. Becker KJ, Baxter AB, Cohen WA, Bybee HM, Tirschwell DL, Newell DW, et al: Withdrawal of support in intracerebral hemorrhage may lead to self-fulfilling prophecies. Neurology 56:766-772, 2001

8. Brickman P, Coates D, Janoff-Bulman R: Lottery winners and accident victims: is happiness relative? J Pers Soc Psychol 36: $917-927,1978$

9. Buchanan AE, Brock DW: Deciding for Others: The Ethics of Surrogate Decision Making. Cambridge: Cambridge University Press, 1989, p 422

10. Carr AJ, Gibson B, Robinson PG: Measuring quality of life: is quality of life determined by expectations or experience? BMJ 322:1240-1243, 2001

11. Christakis NA, Asch DA: Biases in how physicians choose to withdraw life support. Lancet 342:642-646, 1993

12. Christakis NA, Asch DA: Physician characteristics associated with decisions to withdraw life support. Am J Public Health 85:367-372, 1995

13. Christakis NA, Lamont EB: Extent and determinants of error in doctors' prognoses in terminally ill patients: prospective cohort study. BMJ 320:469-472, 2000

14. Counsell C, Dennis M: Systematic review of prognostic models in patients with acute stroke. Cerebrovasc Dis 12:159170, 2001

15. Creutzfeldt CJ, Becker KJ, Weinstein JR, Khot SP, McPharlin TO, Ton TG, et al: Do-not-attempt-resuscitation orders and prognostic models for intraparenchymal hemorrhage. Crit Care Med 39:158-162, 2011

16. Creutzfeldt CJ, Holloway RG: Treatment decisions after severe stroke: uncertainty and biases. Stroke 43:3405-3408, 2012

17. Diringer MN, Edwards DF, Aiyagari V, Hollingsworth H: Factors associated with withdrawal of mechanical ventilation in 
a neurology/neurosurgery intensive care unit. Crit Care Med 29:1792-1797, 2001

18. Emanuel EJ, Fuchs VR: The perfect storm of overutilization. JAMA 299:2789-2791, 2008

19. Epstein RM, Alper BS, Quill TE: Communicating evidence for participatory decision making. JAMA 291:2359-2366, 2004

20. Evans RW: Quality of life. Lancet 338:350-351, 1991

21. Fagerlin A, Ditto PH, Danks JH, Houts RM, Smucker WD: Projection in surrogate decisions about life-sustaining medical treatments. Health Psychol 20:166-175, 2001

22. Fernandes HM, Gregson B, Siddique S, Mendelow AD: Surgery in intracerebral hemorrhage. The uncertainty continues. Stroke 31:2511-2516, 2000

23. Fernandes HM, Mendelow AD: Spontaneous intracerebral haemorrhage: a surgical dilemma. Br J Neurosurg 13:389394, 1999

24. Finley Caulfield A, Gabler L, Lansberg MG, Eyngorn I, Mlynash M, Buckwalter MS, et al: Outcome prediction in mechanically ventilated neurologic patients by junior neurointensivists. Neurology 74:1096-1101, 2010

25. Flaherty ML, Haverbusch M, Sekar P, Kissela B, Kleindorfer D, Moomaw CJ, et al: Long-term mortality after intracerebral hemorrhage. Neurology 66:1182-1186, 2006

26. Foerch C, Lang JM, Krause J, Raabe A, Sitzer M, Seifert V, et al: Functional impairment, disability, and quality of life outcome after decompressive hemicraniectomy in malignant middle cerebral artery infarction. J Neurosurg 101:248-254, 2004

27. Garland A, Connors AF: Physicians' influence over decisions to forego life support. J Palliat Med 10:1298-1305, 2007

28. Gregson BA, Broderick JP, Auer LM, Batjer H, Chen XC, Juvela S, et al: Individual patient data subgroup meta-analysis of surgery for spontaneous supratentorial intracerebral hemorrhage. Stroke 43:1496-1504, 2012

29. Gregson BA, Mendelow AD: International variations in surgical practice for spontaneous intracerebral hemorrhage. Stroke 34:2593-2597, 2003

30. Gries CJ, Curtis JR, Wall RJ, Engelberg RA: Family member satisfaction with end-of-life decision making in the ICU. Chest 133:704-712, 2008

31. Hemphill JC III: Do-not-resuscitate orders, unintended consequences, and the ripple effect. Crit Care 11:121, 2007

32. Hemphill JC III, Bonovich DC, Besmertis L, Manley GT, Johnston SC: The ICH score: a simple, reliable grading scale for intracerebral hemorrhage. Stroke 32:891-897, 2001

33. Hemphill JC III, Newman J, Zhao S, Johnston SC: Hospital usage of early do-not-resuscitate orders and outcome after intracerebral hemorrhage. Stroke 35:1130-1134, 2004

34. Hemphill JC III, White DB: Clinical nihilism in neuroemergencies. Emerg Med Clin North Am 27:27-37, 2009

35. Hoff JT: Editorial comment-International variations in surgical practice for spontaneous intracerebral hemorrhage. Stroke 34:2597-2598, 2003

36. Holloway RG, Benesch CG, Burgin WS, Zentner JB: Prognosis and decision making in severe stroke. JAMA 294:725733, 2005

37. Institute of Medicine, Committee on Quality of Health Care in America: Crossing the Quality Chasm: A New Health System for the 21st Century. Washington, DC: National Academy Press, 2001

38. John EW: Time to tackle unwarranted variations in practice. BMJ 342:687-690, 2011

39. Juvela S, Heiskanen O, Poranen A, Valtonen S, Kuurne T, Kaste M, et al: The treatment of spontaneous intracerebral hemorrhage. A prospective randomized trial of surgical and conservative treatment. J Neurosurg 70:755-758, 1989

40. Kahneman D: Thinking, Fast and Slow. New York: Farrar, Straus and Giroux, 2011
41. Kahneman D, Krueger AB, Schkade D, Schwarz N, Stone AA: Would you be happier if you were richer? A focusing illusion. Science 312:1908-1910, 2006

42. Keirns CC, Goold SD: Patient-centered care and preferencesensitive decision making. JAMA 302:1805-1806, 2009

43. Kelly AG, Hoskins KD, Holloway RG: Early stroke mortality, patient preferences, and the withdrawal of care bias. Neurology 79:941-944, 2012

44. Kirkman MA, Mahattanakul W, Gregson BA, Mendelow AD: The effect of the results of the STICH trial on the management of spontaneous supratentorial intracerebral haemorrhage in Newcastle. Br J Neurosurg 22:739-747, 2008

45. Klein A, Kuehner C, Schwarz S: Attitudes in the general population towards hemi-craniectomy for middle cerebral artery (MCA) infarction. A population-based survey. Neurocrit Care 16:456-461, 2012

46. Lo B, Steinbrook R: Resuscitating advance directives. Arch Intern Med 164:1501-1506, 2004

47. Loewenstein G: Projection bias in medical decision making. Med Decis Making 25:96-105, 2005

48. Maira G, Doglietto F: Intracerebral hemorrhage: a transition phase toward better prognosis. World Neurosurg 78:583585,2012

49. Mckissock W, Richardson A, Taylor J: Primary intracerebral haemorrhage: a controlled trial of surgical and conservative treatment in 180 unselected cases. Lancet 278:221-226, 1961

50. Mendelow AD, Gregson BA, Fernandes HM, Murray GD, Teasdale GM, Hope DT, et al: Early surgery versus initial conservative treatment in patients with spontaneous supratentorial intracerebral haematomas in the International Surgical Trial in Intracerebral Haemorrhage (STICH): a randomised trial. Lancet 365:387-397, 2005

51. Mendelow AD, Gregson BA, Mitchell PM, Murray GD, Rowan EN, Gholkar AR, et al: Surgical trial in lobar intracerebral haemorrhage (STICH II) protocol. Trials 12:124, 2011

52. Morgenstern LB, Hemphill JC III, Anderson C, Becker K, Broderick JP, Connolly ES Jr, et al: Guidelines for the management of spontaneous intracerebral hemorrhage: a guideline for healthcare professionals from the American Heart Association/American Stroke Association. Stroke 41:21082129,2010

53. Mulley AG Jr, Eagle KA: What is inappropriate care? JAMA 260:540-541, 1988

54. Nakano T, Ohkuma H: Surgery versus conservative treatment for intracerebral haemorrhage-is there an end to the long controversy? Lancet 365:361-362, 2005

55. Niemelä M, Hernesniemi J: The risks of surgery in spontaneous supratentorial intracerebral hemorrhages. World Neurosurg 78:581-582, 2012

56. Noble AJ, Schenk T: Which variables help explain the poor health-related quality of life after subarachnoid hemorrhage? A meta-analysis. Neurosurgery 66:772-783, 2010

57. Ouslander JG, Tymchuk AJ, Rahbar B: Health care decisions among elderly long-term care residents and their potential proxies. Arch Intern Med 149:1367-1372, 1989

58. Patil CG, Alexander AL, Hayden Gephart MG, Lad SP, Arrigo RT, Boakye $\mathrm{M}$ : A population-based study of inpatient outcomes after operative management of nontraumatic intracerebral hemorrhage in the United States. World Neurosurg 78:640-645, 2012

59. Pellegrino ED: Decisions to withdraw life-sustaining treatment: a moral algorithm. JAMA 283:1065-1067, 2000

60. Pellegrino ED, Thomasma DC: The anatomy of clinical judgments, in: A Philosophical Basis of Medical Practice: Toward a Philosophy and Ethic of the Healing Professions. New York: Oxford University Press, 1981, p 141

61. Preference-sensitive care. Dartmouth Atlas of Health Care. (http://www.dartmouthatlas.org/downloads/reports/preference_ sensitive.pdf) [Accessed March 11, 2013] 
62. Príncipe-Rodríguez K, Rodríguez-Cintrón W, Torres-Palacios A, Casal-Hidalgo J: Substituted judgement: should life-support decisions be made by a surrogate? P R Health Sci J 18: 405-409, 1999

63. Puetz V, Campos CR, Eliasziw M, Hill MD, Demchuk AM: Assessing the benefits of hemicraniectomy: what is a favourable outcome? Lancet Neurol 6:580-581, 2007 (Letter)

64. Quill TE, Holloway R: Time-limited trials near the end of life. JAMA 306:1483-1484, 2011

65. Quill TE, Holloway RG: Evidence, preferences, recommendations - finding the right balance in patient care. N Engl J Med 366:1653-1655, 2012

66. Qureshi AI, Tuhrim S, Broderick JP, Batjer HH, Hondo H, Hanley DF: Spontaneous intracerebral hemorrhage. N Engl J Med 344:1450-1460, 2001

67. Redelmeier DA, Rozin P, Kahneman D: Understanding patients' decisions. Cognitive and emotional perspectives. JAMA 270:72-76, 1993

68. Rost NS, Smith EE, Chang Y, Snider RW, Chanderraj R, Schwab K, et al: Prediction of functional outcome in patients with primary intracerebral hemorrhage: the FUNC score. Stroke 39:2304-2309, 2008

69. Roth C, Kästner S, Salehi M, Kleffmann J, Böker DK, Deinsberger W: Comparison of spontaneous intracerebral hemorrhage treatment in Germany between 1999 and 2009: results of a survey. Stroke 43:3212-3217, 2012

70. Russell MW, Boulanger L, Joshi AV, Neumann PJ, Menzin J: The economic burden of intracerebral hemorrhage: evidence from managed care. Manag Care Interface 19:24-28, 34, 2006

71. Russell MW, Joshi AV, Neumann PJ, Boulanger L, Menzin J: Predictors of hospital length of stay and cost in patients with intracerebral hemorrhage. Neurology 67:1279-1281, 2006

72. Savulescu J: Rational desires and the limitation of life-sustaining treatment. Bioethics 8:191-222, 1994

73. Schneiderman LJ, Kaplan RM, Pearlman RA, Teetzel H: Do physicians' own preferences for life-sustaining treatment influence their perceptions of patients' preferences? J Clin Ethics 4:28-33, 1993

74. Sepucha KR, Fowler FJ Jr, Mulley AG Jr: Policy support for patient-centered care: the need for measurable improvements in decision quality. Health Aff (Millwood) Suppl Variation:VAR54-VAR62, 2004

75. Shalowitz DI, Garrett-Mayer E, Wendler D: The accuracy of surrogate decision makers: a systematic review. Arch Intern Med 166:493-497, 2006

76. Sulmasy DP, Hughes MT, Thompson RE, Astrow AB, Terry $\mathrm{PB}, \mathrm{Kub} \mathrm{J}$, et al: How would terminally ill patients have others make decisions for them in the event of decisional incapacity? A longitudinal study. J Am Geriatr Soc 55:1981-1988, 2007

77. Sulmasy DP, Snyder L: Substituted interests and best judgments: an integrated model of surrogate decision making. JAMA 304:1946-1947, 2010

78. Swindell JS, McGuire AL, Halpern SD: Shaping patients' decisions. Chest 139:424-429, 2011
79. Teno JM, Fisher E, Hamel MB, Wu AW, Murphy DJ, Wenger NS, et al: Decision-making and outcomes of prolonged ICU stays in seriously ill patients. J Am Geriatr Soc 48 (5 Suppl): S70-S74, 2000

80. Tversky A, Kahneman D: Judgment under uncertainty: heuristics and biases. Science 185:1124-1131, 1974

81. Ubel PA, Loewenstein G, Jepson C: Whose quality of life? A commentary exploring discrepancies between health state evaluations of patients and the general public. Qual Life Res 12:599-607, 2003

82. Ubel PA, Loewenstein G, Schwarz N, Smith D: Misimagining the unimaginable: the disability paradox and health care decision making. Health Psychol 24 (4 Suppl):S57-S62, 2005

83. Vahedi K, Benoist L, Kurtz A, Mateo J, Blanquet A, Rossignol $\mathrm{M}$, et al: Quality of life after decompressive craniectomy for malignant middle cerebral artery infarction. J Neurol Neurosurg Psychiatry 76:1181-1182, 2005

84. Vig EK, Starks H, Taylor JS, Hopley EK, Fryer-Edwards K: Surviving surrogate decision-making: what helps and hampers the experience of making medical decisions for others. $\mathbf{J}$ Gen Intern Med 22:1274-1279, 2007

85. Weeks JC, Cook EF, O’Day SJ, Peterson LM, Wenger N, Reding D, et al: Relationship between cancer patients' predictions of prognosis and their treatment preferences. JAMA 279:1709-1714, 1998

86. Wegwarth O, Schwartz LM, Woloshin S, Gaissmaier W, Gigerenzer G: Do physicians understand cancer screening statistics? A national survey of primary care physicians in the United States. Ann Intern Med 156:340-349, 2012

87. Wennberg DE, Dickens JD Jr, Biener L, Fowler FJ Jr, Soule DN, Keller RB: Do physicians do what they say? The inclination to test and its association with coronary angiography rates. J Gen Intern Med 12:172-176, 1997

88. Wennberg J, Gittelsohn A: Small area variations in health care delivery. Science 182:1102-1108, 1973

89. Wennberg JE: Tracking Medicine: A Researcher's Quest to Understand Health Care. New York: Oxford University Press, 2010

90. Wennberg JE, Blowers L, Parker R, Gittelsohn AM: Changes in tonsillectomy rates associated with feedback and review. Pediatrics 59:821-826, 1977

91. Wennberg JE, Gittelsohn A: Health care delivery in Maine I: patterns of use of common surgical procedures. J Maine Med Assoc 66:123-130, 149, 1975

Manuscript submitted January 15, 2013.

Accepted February 13, 2013.

Please include this information when citing this paper: DOI: 10.3171/2013.2.FOCUS1319.

Address correspondence to: Michael L. Kelly, M.D., Department of Neurosurgery, Cleveland Clinic, 9500 Euclid Avenue, S40, Cleveland, Ohio 44195. email: kellym8@ccf.org. 